\title{
Teaching Teachers in the Planetarium
}

Roland Szostak

Institut für Didaktik der Physik, Universität Münster, Wilhelm-Klemm-Strasse 10, 4400 Münster, Federal Republic of Germany

Many people do not know what a planetarium is. Since this disappointing fact is even true for well-educated people, including students and teachers, many pupils will never hear about planetariums. In order to spread knowledge about planetariums, universities can play a major role. One of the best ways is to visit a planetarium with students, especially those who will become teachers. Such a visit is a very efficient multiplying factor.

But in order to make a planetarium visit efficient, one should not go unprepared. We therefore go with education students who are enrolled in an astronomy course. Before their visit, we inform them about what a planetarium is and about how it is used. We teach them, for example, specific terms of the rotating sky, its coordinates, and the significance of the ecliptic and of retrograde loops. And of course, we teach the students how the sky appears from different latitudes, including the equator and the southern hemisphere. We also teach the technical aspects of how the projector works.

Students visits take place by special arrangement, without any other audience, so all technical details can be discussed individually. The operator can run the machine to answer specific questions that arise. And some of the students can even put their own hands onto the buttons of the control panel to run the machine. After the exclusive technical visit, we usually attend a normal public performance. We see teachers and their classes, so we can observe how children behave and react to the phenomena projected onto the dome.

Students are very motivated by their visit to the planetarium. As a result, they come back with their own classes later on. Such cooperation between university and planetarium is highly recommended. It will help in getting more knowledge about astronomy into schools, promoting a more profound understanding of nature.

\section{Astronomy for the Visually Handicapped}

Pierre Lacombe

Planétarium Dow, 1000 rue Saint-Jacques ouest, Montréal, Québec H3C 1G7, Canada

It is important to add that in addition to the general public and all the students and teachers involved in school systems, the planetarium community in general tries also to reach some special groups of the public. The groups could be those with hearing problems, those who have never seen any stars (the visually handicapped), 
amateur astronomy groups, and even gifted students.

As you can imagine, these special groups represent a very small fraction of our attendance at the planetarium but they need special treatment, and for that reason many planeteria around the world have at one time or another prepared a unique program in the star theater for them, built new and special exhibits, or given technical tours of their installations.

Earlier this year, the Dow Planetarium was involved in an unusual experience. At the planetarium, it is relatively easy to initiate the general public in astronomy. With shows in the star theater, observing sessions, and spectacular exhibits, the public can make direct relations between images and the real celestial objects visible in the night sky. But how can we initiate people who have never seen any stars people without sight?

The Dow Planetarium in collaboration with the Botanical Garden, the Aquarium, and the Zoological Garden of the City of Montreal was involved in an exhibition to initiate these special people to the world of science. Our exhibit was a scale model of the orbits of the nine planets of our solar system. To permit exploring the exhibit, each orbit was drawn in relief so as to be easily located with the fingers and each planet was represented by a unique symbol. Experiments done with the visually handicapped have shown us that this concept was ideal for the exhibit. We also indicated in braille the names of the planets and the sun. But as only a small fraction of these people is able to read braille, an audio-guide describing each planet and the sun was available and highly recommended.

The exhibition was a great success. Imagine, for the first time, a complete scientific exhibition designed especially for the sightless person! At the Planetarium, we have learned a lot about this neglected clientele and the work we have done sets new standards for future exhibits (height, angle, and so on...).

\title{
Planetarium Activities in the Federal Republic of Germany
}

\author{
H.-U. Keller \\ Planetarium Stuttgart, Neckarstrasse 47, D-7000 Stuttgart 1, West Germany
}

The planetarium was invented by the German engineer Walther Bauersfeld of the Carl Zeiss Company in 1919, and the first projection-planetarium in the world was installed in the Deutsches Museum in München (Munich) 1923. Most of the German planetariums were destroyed during World War II. Today, nine major planetariums with dome diameters greater than $15 \mathrm{~m}$ are in operation in the following cities in F.R. Germany; the numbers in brackets are the year of opening, the dome size and the seating capacity: West Berlin (1965; $20 \mathrm{~m} ; 320)$, Bochum $(1964 ; 20 \mathrm{~m}$; $300)$, Hamburg (1933; $20.6 \mathrm{~m} ; 270)$, Mannheim $(1984 ; 20 \mathrm{~m} ; 287)$, München (1925; $15 \mathrm{~m} ; 156)$, Münster $(1981 ; 20 \mathrm{~m} ; 280)$, Nürnberg $(1961 ; 18 \mathrm{~m} ; 255)$, Stuttgart $(1977 ; 20 \mathrm{~m} ; 277)$, and Wolfsburg $(1983 ; 15 \mathrm{~m} ; 148)$. 